(C) 2018. This manuscript version is made available under the CCBY-NC-ND 4.o license http://creativecommons.org/licenses/by-nc-nd/4.0/ 


\section{Accepted Manuscript}

Design and testing of an adhesively bonded CFRP strengthening system for steel structures

S. Chataigner, K. Benzarti, G. Foret, J.F. Caron, G. Gemignani, M. Brugiolo, I. Calderon, I. Piñero, V. Birtel, F. Lehmann

PII: S0141-0296(18)30490-5

DOI: https://doi.org/10.1016/j.engstruct.2018.10.004

Reference: JEST 8459

To appear in: Engineering Structures

Received Date: 14 February 2018

Revised Date: $\quad 26$ September 2018

Accepted Date: 1 October 2018

Please cite this article as: Chataigner, S., Benzarti, K., Foret, G., Caron, J.F., Gemignani, G., Brugiolo, M., Calderon, I., Piñero, I., Birtel, V., Lehmann, F., Design and testing of an adhesively bonded CFRP strengthening system for steel structures, Engineering Structures (2018), doi: https://doi.org/10.1016/j.engstruct.2018.10.004

This is a PDF file of an unedited manuscript that has been accepted for publication. As a service to our customers we are providing this early version of the manuscript. The manuscript will undergo copyediting, typesetting, and review of the resulting proof before it is published in its final form. Please note that during the production process errors may be discovered which could affect the content, and all legal disclaimers that apply to the journal pertain. 


\title{
Design and testing of an adhesively bonded CFRP strengthening system for steel structures
}

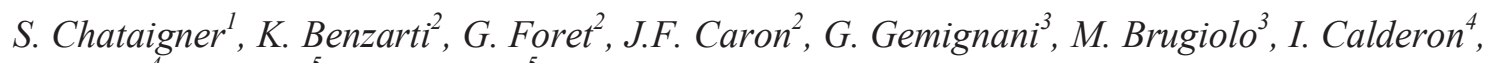

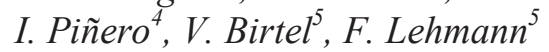 \\ ${ }^{1}$ IFSTTAR, MAST, SMC,F-44344 Bouguenais, France (sylvain.chataigner@ifsttar.fr) \\ ${ }^{2}$ Université Paris-Est, Laboratoire Navier (UMR 8205), IFSTTAR, Ecole des Ponts ParisTech, F- \\ 77447 Marne La Vallée, France \\ ${ }^{3}$ Collanti Concorde, I-31029 Vittorio Veneto, Italy \\ ${ }^{4}$ TECNALIA R\&I, E-48160 Derio - Bizkaia, Spain \\ ${ }^{5}$ MPA, Materials Testing Institute University of Stuttgart, Pfaffenwadring 4, 70569 Stuttgart, Germany
}

\section{ABSTRACT:}

In the framework of sustainable development policies, it is essential that infrastructure owners can rely on effective repair or strengthening solutions, designed and tested in relevance to actual service conditions. In the case of steel structures, fatigue damage is a major concern that can significantly affect the lifespan of the structure, and so far, there are very few operational methods capable of preventing fatigue cracks in the field. Adhesively bonded carbon fiber reinforced polymer (CFRP) composites are being successfully applied to the rehabilitation of concrete structures for more than two decades, and they are currently receiving much interest for the strengthening of steel elements, but mainly for curative purpose after severe damage has occurred.

In the present study, which is part of a European project called FASSTbridge, a specific CFRP system has been developed as a preventive method against fatigue damage of steel structures. The proposed system consists of a commercially available ultra-high modulus (UHM) CFRP composite plate compatible with the stiffness of the host steel structures, which is bonded to the steel support using a novel hybrid epoxy/polyurethane adhesive. A first part of the paper presents the main specifications that should be adopted in the design of CFRP strengthening systems applied to steel structures, and that were identified from an extensive literature survey. These specifications have guided the development of the polymer adhesive and the choice of a peculiar commercial CFRP plate in the preliminary phase of the project. Experimental characterizations were then conducted (i) on the formulated hybrid polymer adhesive to optimize its curing schedule and check the previous specifications are fulfilled, and (ii) on CFRP reinforced steel specimens in order to verify the effectiveness of the proposed strengthening system. This experimental program involved both short term and durability tests that were performed by different laboratories. Such an inter-laboratory study made it possible to verify the performances of the developed strengthening system and to assess the influence of installation parameters and environmental conditions.

Key words: Strengthening, fatigue, steel bridges, CFRP composites, adhesively bonded joints, durability, experimental investigations.

\section{Introduction}

Steel bridges serve as vital components in the transportation infrastructure, especially in densely populated areas. Bridges are frequently cause of major inconveniences on users' comfort (service disturbances, disruptions, accessibility problems, delays, traffic jams) and welfare (obstacles to safety and security, nuisance from noise, vibrations, dust and air pollution). Furthermore, problems derived 
from their dysfunction may affect the economic activity in the surrounding geographical area (transportation, job accessibility, development strategies). In Europe, 15\% of the 300000 bridges are made of steel or consist of hybrid concrete-steel structures [1]. An assessment made in 2014 revealed that approximately $68 \%$ of these steel bridges need structural interventions. In the USA, $34 \%$ of the 599000 bridges are made of steel and among them, approximately $9 \%$ were classified as structurally deficient in 2012, $15 \%$ were functionally obsolete and $9.5 \%$ were both structurally deficient and functionally obsolete [2].

Many of these bridges were constructed according to old standards without any consideration of fatigue issues [3], and for a design service life of 50 years that is coming to its end or has already been exceeded. In addition, the exponential growth of traffic flows and carriage loads during the last decades has led to a significant increase in fatigue related damages, hence reducing the remaining service life of these steel structures [4]. So far, the mainstream approach against fatigue problems has been a reactive strategy based on maintenance or repair operations that are undertaken after occurrence of cracks in the structure. With a bridge stock that is inevitably ageing, it is necessary to change the paradigm and widely adopt a preventive strategy.

Existing reinforcement or repair methods for steel structures are mostly based on the installation of additional steel plates attached by either riveting, bolting or welding [5] (Fig.1.a). These methods suffer from high additional weight, difficult implementation (labour-intensive and disruptive to traffic), and may decrease the fatigue life expectancy due to local stress concentrations in the connection areas [6]. Carbon Fibre Reinforced Polymers (CFRP) composites, although more expensive than steel plates, present several and relevant advantages that make them suitable and cost effective for steel bridges retrofitting. Their installation is less time consuming compared to traditional repair solutions (i.e. from one month to a few days, therefore less traffic disruptive) and such composite materials exhibit a high strength-to-weight ratio, excellent fatigue properties, high durability and versatility, and they are also easy to handle and apply without heavy equipment [7-9] (Fig.1.b). Their attachment to the existing structure can be achieved either by adhesive bonding or using frictional equipment [10]. Several guidelines have been proposed so far to ensure a good quality of CFRP installation on steel structures [11-15]. Previous investigations proved that there are two main options for the design of cost effective CFRP strengthening systems applied to steel structures [16]: either the use of ultra-high modulus (UHM) CFRP reinforcement [13] or the use of prestressed CFRP composite plates [17-18].

CFRPs have been widely adopted in the field for the strengthening of concrete structures, but their applications on steel structures still remain very limited, although their efficiency has been demonstrated for the reinforcement of cracked steel elements [19-24] and for structural strengthening [25-27]. The main technical barrier to the adoption of this technique relates to reliability/durability concerns regarding the attachment to the host structure (i.e., the chemical bond created by the adhesive layer) when subjected to combined outdoor environment and mechanical loading. In this context, high quality adhesives are required to ensure cost-effective and durable strengthening interventions [28].

In the present study, an adhesively bonded CFRP strengthening system has been specifically designed to prevent fatigue damage of steel structures, based on the use of a commercially available UHM CFRP plate combined with a novel formulated polymer adhesive. This latter consists of a hybrid epoxy/polyurethane formulation, which is intended to provide enhanced adhesion on steel substrates and improved resistance to fatigue and humid ageing compared to traditional epoxies. Of course, due to the fixed shape and the high stiffness of the UHM CFRP plate, such a reinforcement solution is only adapted to plane surfaces and is not compliant with non-planar critical details [29].

The first section of the paper is devoted to the development of the hybrid polymer adhesive. Justifications are given regarding the main specifications that guided the formulation work, and a description of experimental investigations performed on the bulk adhesive is then provided. The second section presents the experimental work conducted on adhesively bonded assemblies to check mechanical compatibility of the various components (steel / hybrid adhesive / UHM CFRP). The last 
section focuses on durability investigations, with a special emphasis on the influence of environmental conditions and fatigue loading on the performances of UHM CFRP strengthened steel elements.

\section{Development and assessment of the hybrid polymer adhesive}

An extensive literature review was carried out to define the specifications of the polymer adhesive in case of strengthening application on steel structures. Several requirements were identified, which are summarized as follows:

- A major constraint relates to the service temperature range of steel structures, which can be estimated between $-35^{\circ} \mathrm{C}$ and $56^{\circ} \mathrm{C}$ according to main existing North-American and European guidelines $[30 ; 31]$. It is admitted that the maximum service temperature can be significantly higher compared to that of concrete structures, due to thermal properties of steel. In this context, it was decided to adopt a safety margin of $15^{\circ} \mathrm{C}$ above the reported maximum service temperature of $56^{\circ} \mathrm{C}$ for the glass transition temperature of the adhesive $(\mathrm{Tg})$, and this latter should therefore be higher than $71{ }^{\circ} \mathrm{C}$. Available commercial adhesives developed for strengthening application on concrete substrates usually display low $T g$ values in the range 45$55^{\circ} \mathrm{C}$ after cure at ambient temperature (as measured by DSC - Differential Scanning Calorimetry [32]), and even in the case of an additional post-cure treatment, the specification $\mathrm{Tg}>71^{\circ} \mathrm{C}$ cannot be achieved in practice. It is thus necessary to develop a specific adhesive formulation that can meet this requirement.

- The workability of the polymer adhesive must be compatible with an easy application on construction site. Therefore, a pot life over 30 minutes is required, so that operators have enough time for installation of the composite reinforcements.

- Finally, in order that the adhesive remains structural and on the basis of preliminary investigations, it was decided to adopt a minimum tensile strength requirement of $35 \mathrm{MPa}$.

\subsection{Formulation work and optimization of the cure schedule}

In this context, a bi-component polymer adhesive system was formulated, consisting of a hybrid epoxy/polyurethane resin and an amine hardener, and complying with the previous specifications. As previously stated, the purpose of introducing a polyurethane compound in the resin was to enhance the fatigue behaviour by providing additional flexibility in the polymer network, and to increase the moisture resistance of the adhesive. The formulation work was conducted by the industrial partner of the project (Collanti Concorde, Italy) following an iterative trial and error method. Regarding reactive monomer compounds, all tentative systems contained 7 wt. $\%$ of polyurethane, 30 wt. $\%$ of kaolin fillers and polyamide fibers. After multiple attempts, a successful candidate formulation was obtained, whose main physical properties are reported in Table 1. This system was named UREPOX Extra $2 \mathrm{C} / 2 \mathrm{~B}$ by the manufacturer.

As shown in Table 1, the pot life was close to 30 minutes at $20^{\circ} \mathrm{C}$ for a mass of $2.5 \mathrm{~kg}$ of polymer adhesive. More extended pot lives are thus expected for lower amount of adhesive. As $1 \mathrm{~kg}$ pots are likely to be used in the field for strengthening applications on steel structures, it can be concluded that specification on workability (pot life $\geq 30$ minutes) is fulfilled by UREPOX Extra $2 \mathrm{C} / 2 \mathrm{~B}$ adhesive.

Differential scanning calorimetry (DSC) was used to determine the glass transition temperature ( $T g$ ) of the bulk hybrid adhesive. Samples (few $\mathrm{mg}$ of adhesive mix) were analysed using a DSC 250 Discovery apparatus (TA Instrument, USA), with a ramp of temperature from $-30^{\circ} \mathrm{C}$ to $200^{\circ} \mathrm{C}$, at a heating rate of $10^{\circ} \mathrm{C} / \mathrm{min}$. For adhesive samples cured at $20^{\circ} \mathrm{C}$ for few days, a low $\mathrm{Tg}$ around $50^{\circ} \mathrm{C}$ was obtained. From this result, it can be concluded that cure at ambient temperature $\left(20^{\circ} \mathrm{C}\right)$ leads to an incomplete cross-linking of the material. After a second DSC run performed on the same sample (which can be considered as fully cured due to post-cure at high temperature during the first DSC run), a glass transition temperature $T g_{\infty}$ of $76^{\circ} \mathrm{C}$ was found. This result clearly shows that UREPOX Extra 2C/2B can comply with $T g$ specification $\left(T g>71^{\circ} \mathrm{C}\right)$, provided an adequate post-cure schedule is applied after initial cure at room temperature. 
A further step consisted in the optimization of the post-cure procedure. DSC analyses were performed on series of samples that had previously been subjected to various treatments: a control specimen was cured at $20^{\circ}$ for 24 hours, while the other samples were first cured in the same condition and then post-cured for one hour at various temperatures in the range $60-100^{\circ} \mathrm{C}$. As examples, Figs. 2.a and 2.b displays DSC thermograms obtained for the control sample cured at ambient temperature, and for the specimen subjected to an additional post-cure at $80^{\circ} \mathrm{C}$, respectively. Table 2 provides the values of $T g$ determined from DSC thermograms. The degree of cure $\alpha$ was also calculated from the enthalpy of the residual exothermic peak $\Delta H r$ and the total heat of polymerization $(\Delta H=176 \mathrm{~J} / \mathrm{g}$, as determined experimentally on the fresh mix) according to:

$\alpha=\left(1-\frac{\Delta H_{r}}{\Delta H}\right) \cdot 100$

Figure 3 depicts the plots of $\mathrm{Tg}$ versus the post-cure temperature (the duration of the post-cure treatment was fixed at $1 \mathrm{~h}$ ). As stated before, it is found that without additional post-cure, $T g$ remains very low and the polymerization doesn't achieve completion (as revealed by the residual exothermic peak on the DSC thermogram in Fig 2.a, and by the degree of cure $\alpha=0.93$ ). When applying an additional post-cure treatment, it is found that both $T g$ and the degree of cure increase as a function of post-cure temperature. Following cure at $100^{\circ} \mathrm{C}$, the value of $T g$ becomes close to $T g$ and the degree of cure is very close to $100 \%$, which means the polymer network is almost fully crosslinked. Nevertheless, a post cure of 1 hour at $80^{\circ} \mathrm{C}$ is found satisfactory for overpassing $\mathrm{Tg}$ specification $(\mathrm{Tg}>$ $71^{\circ} \mathrm{C}$ ) and reaching a degree of cure higher than $99 \%$. This latter post-cure condition has been selected for the final reinforcement solution.

A last question is concerned with the sequence of the initial cure at ambient temperature and the following post-cure treatment. This is a crucial aspect concerning the application on construction site, as the traffic disruption time must be as reduced as possible. It was proposed to consider the gel time (evaluated at $1 \mathrm{~h} 30$ at $20^{\circ} \mathrm{C}$, as mentioned in Table 1) as the criterion for evaluating the time during which it is necessary to maintain the adhesive mix at ambient temperature before applying the postcure treatment. After gelation, the mix is not considered as a liquid material anymore and a tridimensional polymer network is formed at the macroscopic scale. Thus, the geometrical characteristics of the adhesive joint are not expected to vary too much after this stage. Using a margin, it was chosen to respect a waiting time of at least 2 hours at ambient temperature before applying the post-cure treatment. This specification is valid for an outdoor temperature higher than $20^{\circ} \mathrm{C}$, but should be revised at lower temperatures by performing additional rheological tests (in this case, the gel time is likely to be significantly increased).

\subsection{Thermo-mechanical behaviour of the polymer adhesive}

Quasi static tensile tests were carried out on parallelepiped samples (dimension 3.0x0.7 $28.0 \mathrm{~mm}^{3}$ ) of UREPOX Extra 2C/2B adhesive using a Dynamic Mechanical Analysis - DMA apparatus (VA 2000 from Metravib, France). Tests were performed at controlled displacement rate $(1 \mathrm{~mm} / \mathrm{min})$ and at various stabilized temperatures: $25^{\circ} \mathrm{C}, 40^{\circ} \mathrm{C}, 50^{\circ} \mathrm{C}, 60^{\circ} \mathrm{C}$ and $70^{\circ} \mathrm{C}$. In order to check the effectiveness of the post-cure treatment, series of tests were made on both control samples (cured at $20^{\circ} \mathrm{C}$ for few days) and post-cured samples (initial cure at $20^{\circ} \mathrm{C}$ for few days, followed by a post-cure for $1 \mathrm{~h}$ at $80^{\circ} \mathrm{C}$ ). At least, three tests were repeated for each test condition and each type of specimen.

The evolution curves of the mechanical properties (tensile Young's modulus, tensile strength and elongation) have be plotted as a function of the test temperature on Figure 4. Error bars are also displayed based on calculated standard deviations. The following trends can be pointed out:

- For control specimens without post cure, significant drop of properties (Young's Modulus and tensile strength) are observed from $40^{\circ} \mathrm{C}$, together with an increase in the ultimate elongation. 
- For post-cured specimens, the drop of modulus and strength is delayed over $60^{\circ} \mathrm{C}$ and the increase in elongation is reduced significantly. This confirms that post-cure has enhanced very significantly the thermomechanical behaviour of the UREPOX adhesive.

- In addition, it is to note that the tensile modulus at $25^{\circ} \mathrm{C}$ is close to $35 \mathrm{MPa}$ for the post-cured material, which also complies with the defined specifications.

To complete the discussion, it is proposed to compare the thermomechanical behavior of UREPOX Extra $2 \mathrm{C} / 2 \mathrm{~B}$ adhesive with that of two commercial products available on the market and commonly used on construction sites to bond CFRP composites on concrete structures; these commercial systems will be named adhesive A and adhesive B in the following. Tests were performed by DMA (VA 2000 apparatus from Metravib Company) in dynamical mode. Parallelepiped samples were subjected to sinusoidal load (traction/compression) with an imposed displacement amplitude of 5 microns. Simultaneously, a ramp of temperature at a heating rate of $5^{\circ} \mathrm{C} / \mathrm{min}$ was applied to the sample. This made it possible to determine the evolution of the tensile storage modulus ( $\left.E^{\prime}\right)$ as a function of temperature.

Samples were prepared using the same curing conditions as in the field: UREPOX Extra $2 \mathrm{C} / 2 \mathrm{~B}$ was cured according to the optimized schedule presented in section 3.1 (cure at $20^{\circ} \mathrm{C}+$ post cure at $80^{\circ} \mathrm{C}$ for 1 hour $)$; the 2 other adhesives $\mathrm{A}$ and $\mathrm{B}$ were only cured at ambient temperature $\left(20^{\circ} \mathrm{C}\right.$ for few days in the present case) without post-cure, as prescribed for bonding CFRP plates on concrete structures. Figure 5 shows the evolutions of the tensile storage modulus $E$ ' versus temperature for the different tested materials. From this Figure, it is found that:

- The drop of properties related to the glass transition is observed at much higher temperature for UREPOX Extra $2 \mathrm{C} / 2 \mathrm{~B}$ (onset around $65^{\circ} \mathrm{C}$ ) than for the two other materials (onset around $50-55^{\circ} \mathrm{C}$ ). This can be assigned to the beneficial effect of the post-cure treatment which has increased $T g$ in the case of the UREPOX Extra 2C/2B system.

- When focusing on the modulus at room temperature $\left(25^{\circ} \mathrm{C}\right)$, adhesive $\mathrm{B}$ has a higher modulus due to a high filler content around $80 \mathrm{wt} \%$. Nevertheless, the modulus of UREPOX Extra $2 \mathrm{C} / 2 \mathrm{~B}$ is found equivalent (even slightly higher) compared to that of Adhesive A. Therefore, post-cured UREPOX adhesive is in line with some existing commercial products in terms of stiffness.

3 Mechanical evaluation of the adhesively bonded steel/UHM-CFRP assembly

Preliminary mechanical investigations were carried out on the overall assembly to check the compatibility of the cured UREPOX Extra 2C/2B adhesive and the chosen UHM-CFRP plate, and to determine several key design parameters, such as the ultimate capacity of the assembly or its characteristic anchorage length [33].

The chosen UHM CFRP plate was provided by Epsilon Composite (Gaillan en Medoc, France). It is a pultruded composite that exhibits a tensile axial modulus of $460 \mathrm{GPa}$, and has one peel-ply on each face in order to facilitate the installation procedure.

The surface preparation of the adherents was designed on the basis of preliminary investigations and existing literature, in order to obtain a cohesive failure in the adhesive or the composite plate when testing the bonded assemblies [34-35]. It consisted in sandblasting and degreasing of steel surfaces (medium roughness and SA 2.5 cleanliness level), while for CFRP plates, the peel-plies where removed and the surface was just degreased using acetone. After bonding operations, the thickness of the adhesive layer was around $1 \mathrm{~mm}$ for all CFRP/steel assemblies.

\subsection{Double lap shear tests}

In order to investigate the shear behaviour of the UHM-CFRP/steel assembly, double strap shear fracture tests (also named double-lap tests) were performed as recommended in $[15 ; 36]$. Based on previous studies $[32 ; 36]$, this test was adopted by the three laboratories involved in this experimental program. The chosen geometry for double-lap shear test specimens is presented in Figure 6. A 
minimum bonded length of $200 \mathrm{~mm}$ was adopted, which is greater than the value of the anchorage length (around $150 \mathrm{~mm}$ according to the literature). Spew fillet of the adhesive was adopted on the joint edges in order to optimize the joint capacity, as advised in [13]. In each laboratory, tests were performed on a universal testing machine at a constant displacement rate of $0.5 \mathrm{~mm} / \mathrm{s}$, as recommended in [15]. Each partner tested three samples. A long preliminary work was necessary to optimize the procedure for sample preparation, as this latter has a strong impact on the test results. The UREPOX adhesive was cured according to the schedule defined in Section $2\left(2\right.$ hours cure at $20^{\circ} \mathrm{C}$, followed by $1 \mathrm{~h}$ post-cure at $80^{\circ} \mathrm{C}$ either in a dedicated oven or by means of a regulated heating blanket similar to that used in the field). Some of the samples were instrumented using strain gages (Figure 7), in order to check alignment and symmetry of the specimens, and to analyze strain profiles along the lap joint, as proposed in [37].

Results collected by the three laboratories are given in Table 3. Mixed failure modes were observed for all specimens (cohesive in the adhesive layer and interlaminar in the UHM-CFRP plate) (Figure 8). Regarding ultimate capacities, a maximum dispersion around $14 \%$ was obtained, indicating a rather high sensitivity of the system. This is slightly higher to former investigations conducted on steel specimens reinforced by regular modulus CFRP plates [33], which is mainly due to the mixed failure mode. From these results, a value of $163 \mathrm{kN}$ was adopted for the ultimate capacity of the bonded joint.

\subsection{Determination of the anchorage length}

In order to visualize the shear stress transfer process through the adhesively bonded joint, Figure 9 displays a plot of the measured strain values versus the abscissa along the lap joint, for several load levels (the origin of $x$-axis corresponds to the loaded edge of the bonded joint). It is found that the load transfer occurs near the edge zones $(60 \mathrm{~mm}$ on the left side and $60 \mathrm{~mm}$ on the right side of the joint). This result is in agreement with elastic modelling of stress transfer through adhesive joints presented in [38]. As there is no transfer in the central part of the specimen (proving that the bonded length is larger than the effective transfer length), the characteristic anchorage length can be assessed to be around $120 \mathrm{~mm}$. In addition, Figure 9 does not reveal any non-linear effects up to $140 \mathrm{kN}$, as strain profiles seem to be linearly correlated to the applied load.

\subsection{Determination of a cohesive zone model}

Several authors have proposed to apply cohesive zone models in the case of adhesively bonded joints [35-36; 39-42]. Based on the method proposed in reference [39] and using experimental strain data, a cohesive zone model (shear versus slip curves) was constructed, as illustrated in Figure 10.

Typically, when a specimen fails by cohesive failure in the adhesive layer, a bilinear model is obtained. The shape of the model may be bilinear or exponential, which has negligible influence on the results [42]. An example of classical model obtained in the literature is given in Figure 10 [36; 4041].

In our case, the failure mode is mixed, indicating that the damage of the adhesive is not complete before failure. This may explain why only the first part of the model was able to fit experimental data in Figure 10, and suggests that there is a strong competition between adhesive damage and interlaminar CFRP damage. These observations are in close agreement with [42] and show that an elastic modelling approach may be sufficient in our case to assess both service and ultimate capacities of the adhesively bonded joint.

\subsection{Flexure and double strap tests}

In addition to the classical double lap shear test presented in section 3.1, additional double strap and flexure tests were performed in one of the laboratory (IFSTTAR) using high yield stress steel in order to avoid any yielding of the steel plates during the investigations (Figure 11). Very similar failure modes were observed compared to the previous double-lap-shear tests, and the results in terms of ultimate capacity, dispersion and ultimate CFRP strain (measured by resistive strain gages) are given in Table 4. 
A good repeatability was obtained for the three types of tests (double lap, double strap and flexure). In addition, it is important to note that ultimate strains are well above values required for old steel structures in the case of the double lap and flexure tests. Regarding double strap test, the ultimate strain was of the same order of the yield strain of old steel materials (S235), showing that the proposed system is suitable for application on old steel structures.

Experimental ultimate strains were also compared to theoretical values in Table 4 (calculation based on Bernoulli's hypothesis, by considering a linear strain across the section). A good correlation was obtained for the double lap and double strap test configurations. Differently, regarding the flexure test, Bernoulli's hypothesis was not verified, as the shear behaviour of the CFRP plate is strongly affected by the polymer matrix.

For both flexure and double strap tests, strain measurements made it possible to determine the characteristic anchorage length of the system. This characteristic length was estimated around $120 \mathrm{~mm}$, in accordance with previous results of double lap shear tests.

\subsection{Determination of a failure criterion}

In order to assess different failure criteria and more particularly the one proposed in [14] and Tresca criterion used in [43], an elastic finite element modelling approach of the different tested geometries was implemented on Abaqus commercial code. Results in terms of peel stress and shear stress profiles at average ultimate capacities are given in Figure 12 for the three selected geometries. Based on these results, the maximum shear and peel stress values were determined and different criteria were assessed in Table 5. It can be seen that for this particular case, mixed failure criterion doesn't work, which is in agreement with reference [43]. As in our case, there is little damage of the adhesive before failure, the maximum shear stress criterion seems to be suitable (variation between 52 and $67 \mathrm{MPa}$ ).

4 Sensitivity and durability assessment of the FASSTbridge strengthening system

On the basis of previous results reported in section 3, an additional test program was proposed:

- to assess the sensitivity of test results to the thickness of the adhesive layer as this geometrical parameter may vary quite significantly in the field,

- to verify the effect of temperature on mechanical performances of the bonded assembly,

- to investigate the durability of the proposed strengthening solution, as this latter remains a key issue for structural bonded assemblies. A literature review dedicated to the durability of CFRP strengthening systems $[35,44-50]$ was undertaken and highlighted that moisture and cyclic mechanical loading are the main factors likely to affect the long-term behaviour of the repaired structure. For this reason, an emphasis was made on these aspects.

4.1 Influence of the thickness of the adhesive layer and effect of the test temperature

Series of double lap shear tests (Figure 6) were first performed to assess the influence of the adhesive thickness and the effect of temperature on the ultimate capacity of the UHM CFRP/steel bonded assembly.

Mixed failure modes were obtained in all cases (cohesive in the adhesive layer and interlaminar in the composite plate), in accordance with previous results of section 3.1 (Figure 8).

In Figure 13.a, residual ultimate capacities of the bonded assemblies are plotted against both the thickness of the adhesive layer measured at the beginning of the sample preparation, and the thickness measured after squeezing and polymerization of the adhesive (each dot correspond to an experimental result). Of course, after squeezing, a decrease in thickness is observed compared to the initial thickness, but globally, final values are in the range $0.9-1.5 \mathrm{~mm}$, which is consistent with usual 
thicknesses obtained in the field.. From Figure 13.a, no clear influence of the adhesive thickness on the ultimate capacity of UHM-CFRP/steel assemblies was found, suggesting that this parameter has a negligible impact over the considered variation range. This is an important result, as a fixed value of the average joint thickness can be considered in the design procedure of the bonded assembly.

In Figure 13.b, average ultimate capacities of UHM-CFRP/steel bonded assemblies are plotted as a function of the test temperature. Error bars are also displayed, based on standard deviations calculated from 3 repeated tests at each temperature level.

This graph reveals a strong influence of the test temperature on the ultimate capacity. In the range $20^{\circ} \mathrm{C}$ to $45^{\circ} \mathrm{C}$, a quasi-linear increase in ultimate capacity is observed as a function of temperature. Then, the ultimate capacity decreases as temperature approaches the glass transition temperature of the polymer adhesive. This result is in agreement with literature [28] and shows that the shear capacity of the assembly is not degraded between $20^{\circ} \mathrm{C}$ and the maximum service temperature of steel structures. In addition, it confirms that a safety margin should be respected between the maximum service temperature and the glass transition temperature. Besides, at cold temperature $\left(-20^{\circ} \mathrm{C}\right)$, the capacity is found to be about $50 \%$ lower compared to the value determined at $20^{\circ} \mathrm{C}$. Nevertheless, additional investigations are needed to check these results (especially at cold temperatures).

\subsection{Moisture ageing}

In order to investigate the influence of moisture on the durability of the bonded assembly, UHMCFRP strengthened steel specimens were exposed in climatic chambers at $40^{\circ} \mathrm{C}$ and $95 \% \mathrm{RH}$, as recommended in [44]. These conditions were intended to accelerate the moisture sorption phenomenon, while keeping the temperature value below the glass transition temperature of the adhesive. Both single lap shear tests as described in [35] and double lap shear tests (as presented in Figure 6) were carried out in two different laboratories (IFSTTAR and TECNALIA). Series of three tests were done for the initial test, and after 1000 hours and 3000 hours of exposure. All samples were prepared using a surface protection very similar to the one applied on site, i.e. a surface coating intended for protecting underlying steel from corrosion.

Residual capacities of the specimens are plotted versus ageing time in Figure 14. These results suggest that there is no significant influence of moist ageing on the ultimate capacity of bonded assemblies up to 3000 hours, which is in agreement with another study from the literature [35]. Additional investigations concerning freeze-thaw effects are currently under progress.

\subsection{Fatigue test on double lap joints}

The proposed strengthening solution is designed to prevent fatigue damage of the host steel structure, and it is thus essential to check its fatigue performance. As raised in [28; 51], cyclic loading may slightly deteriorate the ultimate static capacity of the adhesively bonded joint up to $30 \%$. Nevertheless, regarding the fatigue resistance of the adhesively bonded joint, very scarce data is available in the literature.

It was thus decided to investigate the fatigue resistance of the developed reinforcement system, in order to check its effectiveness. In this line, a series of tests was performed using the double lap joint configuration depicted in Figure 6. Based on a literature review, frequencies in the range $4-7 \mathrm{~Hz}$ and a load ratio $\mathrm{R}$ (ratio between minimum and maximum stresses) equal to 0.1 were selected for the test procedure. Different load or stress amplitudes were investigated (from 30 to $50 \%$ of the ultimate static capacity of the assembly tested in the double lap shear configuration).

Experimental results are displayed in Figure 15. All points on the graph correspond to sample failures except the ones obtained at $30 \%$ of the ultimate static capacity, for which the load amplitude was increased after 2 and 5 million cycles (grey arrow). Fatigue failures occurred in a mixed mode very similar to the static failure mode, in agreement with [28]. 
A sketch of resulting Wöhler curve is also depicted in Figure 15 for specimens made with Urepox Extra $2 \mathrm{C} / 2 \mathrm{~B}$. This must be carefully considered as it is based on few experimental results. However, it allows comparing with experimental data available in the literature [52] for samples made with 2 other adhesive products from the market (named adhesives $\mathrm{C}$ and D), Results show that higher number of cycles are globally achieved at a given load level with Urepox system compared to the other commercial adhesives for which the endurance limit is close to $20 \%$ of the static ultimate capacity. In reference [14] it is recommended to adopt a fatigue limit equal to $20-30 \%$ of the static strength if no data is available regarding the fatigue resistance. According to the present experimental investigation, a limitation of service load to $30 \%$ of the ultimate static capacity of the assembly seems acceptable for the developed reinforcement system.

\section{Conclusions}

Transport infrastructures are inevitably ageing over the world, and cost-effective solutions for extending their service life are urgently needed. In the case of steel structures, CFRP strengthening systems are currently being considered as an interesting method, not only for the rehabilitation of deficient structures, but also for the prevention of fatigue damage. In this context, several technical solutions have been identified, based on the use of ultra-high modulus (UHM) CFRP plates or prestressed CFRP composites, and considering different possible assembling methods such as adhesive bonding or frictional clamps. In the present study, an emphasis was made on the development and the evaluation of an adhesively bonded UHM CFRP strengthening system. This latter consists of a commercially available UHM CFRP plate, combined with a hybrid epoxy/ polyurethane (PU) adhesive which has been specifically formulated for this application.

A preliminary literature review focusing on strengthening solutions applicable to steel structures led to the definition of key specifications for the polymer adhesive, in terms of glass transition temperature $(\mathrm{Tg})$, workability and mechanical strength. Extensive work was then dedicated to the formulation of a hybrid epoxy/PU adhesive meeting these specifications, and to the optimization of a 2-step polymerization schedule, that eventually consisted in an initial cure at ambient temperature for at least 2 hours, followed by a post-cure at $80^{\circ} \mathrm{C}$ for 1 hour. The obtained mechanical properties of the adhesive were found to be in line of existing commercial products. Yet, thermo-mechanical characterizations of the bulk adhesive confirmed the effectiveness of the post-cure treatment that enables overpassing the specification on $\operatorname{Tg}\left(>71^{\circ} \mathrm{C}\right)$.

Mechanical investigations were then carried-out on UHM-CFRP/steel assemblies to assess the compatibility of the formulated hybrid polymer adhesive with both adherents. Tests were performed under various configurations (double lap shear test, flexure test, double strap test) to evaluate the failure modes and ultimate capacities of the bonded assemblies, the ultimate strain in the CFRP plates, and the repeatability on test results (in terms of dispersion). This work showed that good repeatability was achieved whatever the test configuration, hence confirming the robustness of the proposed experimental protocol for sample preparation. Furthermore, ultimate strain levels obtained on laboratory specimens were found to be much higher than actual strain expected in the field, which is quite promising for the proposed strengthening solution. Finally, the anchorage length of the bonded UHM-CFRP/steel assembly was determined $(\sim 120 \mathrm{~mm})$ and a cohesive zone model was proposed, which were both in agreement with existing literature.

Additional investigations showed that the adhesive thickness (in the range $0.9-1.5 \mathrm{~mm}$ ) had negligible impact on mechanical performances of UHM-CFRP strengthened steel specimens and that elevated temperatures up to $55^{\circ} \mathrm{C}$ did not deteriorate the ultimate capacity. Differently, cold temperature ($20^{\circ} \mathrm{C}$ ) was found to reduce significantly the ultimate capacity by $50 \%$.

Finally, an experimental plan was undertaken to assess the durability of the proposed system under moist condition and mechanical fatigue cycling. The first results of this ongoing program showed that 
moisture didn't affect the ultimate properties of bonded UHM-CFRP/steel assemblies (at least for those protected by an anti-corrosion coating) and that fatigue endurance limit was reached for a load around $30 \%$ of the ultimate static capacity. This is higher than the limit of $20 \%$ reported in a previous study for specimens based on other adhesive products from the market, which demonstrates the superior fatigue behaviour of the developed FASSTbridge solution.

This study was carried out in the framework of an Infravation European project called FASSTBridge. It is to note that the strengthening system presented in this paper was also evaluated during a site demonstration that took place in 2017 on a hybrid steel-concrete bridge located near Madrid in Spain (Jarama bridge). Details regarding the objectives, results and deliverables of this project are available on the institutional website: fasstbridge.eu.

Acknowledgements

The authors wish to acknowledge Epsilon Composite Company for supporting the study.

This work is part of the FASSTBRIDGE project. This project has received funding from the European Union's Seventh Framework Programme for research, technological development and demonstration under grant agreement no 31109806.0008 .

FASSTbridge is co-funded by Funding Partners of The ERA-NET Plus Infravation and the European Commission. The Funding Partners of the Infravation 2014 Call are:

MINISTERIE VAN INFRASTRUCTUUR EN MILIEU, RIJKSWATERSTAAT, BUNDESMINISTERIUM FÜR VERKEHR, BAU UND STADTENTWICKLUNG, DANISH ROAD DIRECTORATE, STATENS VEGVESEN VEGDIREKTORATET, TRAFIKVERKET - TRV, VEGAGERĐIN, MINISTERE DE L'ECOLOGIE, DU DEVELOPPEMENT DURABLE ET DE L'ENERGIE, CENTRO PARA EL DESARROLLO TECNOLOGICO INDUSTRIAL, ANAS S.p.A., NETIVEI, ISRAEL - NATIONAL TRANSPORT INFRASTRUCTURE COMPANY LTD, FEDERAL HIGHWAY ADMINISTRATION USDOT.

\section{REFERENCES:}

[1] Ye XW, Su YH, Han JP Han. A State-of-the-Art Review on Fatigue Life Assessment of Steel Bridges. Mathematical Problems in Engineering, 2014.

[2] Lee SK. Current State of Bridge Deterioration in the U.S., Rutgers University, Piscataway, New Jersey, 2012.

[3] Palmer T. The development of welded steel fatigue design guidelines, Taylor Machine Works. Machine Design, 2014.

[4] Kühn B, Lukic M, Nussbaumer A, Günther HP, Helmerich R, Herion S, Kolstein MH, Walbridge S, Androic B, Dijkstra O, Bucak O. Assessment of Existing Steel Structures: Recommendations for Estimation of Remaining Fatigue Life. Joint Research Centre Report, 2008.

[5] FHWA. Manual for Repair and Retrofit of Fatigue Cracks in Steel Bridges. Publication No. FHWA-IF-13-020, 2013.

[6] Karbhari VM. Rehabilitation of metallic civil infrastructures using fiber-reinforced polymer (FRP) composites. Woodhead Publishing, 2014

[7] Tavakkolizadeh M, Saadatmanesh H. Fatigue strength of steel girders strengthened with carbon fiber reinforced polymer patch. Journal of Structural Engineering, Vol.129 (2), 2003, 186-196.

[8] Bocciarelli M, Colombi P, Fava G, Poggi C. Fatigue performance of tensile steel members strengthened with CFRP plates. Composite Structures, Vol. 87 (4), 2003, 334-343. 
[9] Miller TC, Chajes MJ, Mertz DR, Hastings JN. Strengthening of a steel bridge girder using CFRP plates. Journal of Bridge Engineering, Vol. 6, no.6, 2001, 514-522.

[10] Kianmofrad F, Ghafoori E, Elyasi M, Motavalli M, Rahimian M. Strengthening of metallic beams with different types of pre-stressed un-bonded retrofit systems. Composite Structures, Vol. 159, 2017, 81-95.

[11] Moy S. ICE Design and Practice Guides - FRP Composites Life Extension and Strengthening of Metallic Structures. London: Thomas Telford Publishing, 2001.

[12] Cadei JMC, Stratford JT, Holloway LC, Duckett WG. Strengthening metallic structures using externally bonded fibre-reinforced polymers. London: CIRIA, 2004.

[13] Schnerch D, Dawood M, Rizkalla S. Design guidelines for the use of HM strips: strengthening of steel concrete composite bridges with high modulus carbon fiber reinforced polymer (CFRP) strips. North Carolina State University, 2007.

[14] CNR. CNR-DT-202/2005, Guidelines for the design and construction of externally bonded FRP systems for strengthening existing structures. Rome: National Research Council, 2007.

[15] DNV. RP-C301, Design, fabrication, operation and qualification of bonded steel repair of steel structures. Det Norske Veritas, 2012.

[16] Ghafoori E, Motavalli M, Zhao X-L, Nussbaumer A, Fontana M. Fatigue design criteria for strengthening metallic beams with bonded CFRP plates. Engineering Structures, Vol. 101, 2015, 542557.

[17] Ghafoori E, Motavalli M. A Retrofit Theory to Prevent Fatigue Crack Initiation in Aging Riveted Bridges Using Carbon Fiber-Reinforced Polymer Materials. Polymers, Vol. 8, 2016, 308.

[18] Ghafoori E, Motavalli M, Nussbaumer A, Herwig A, Prinz GS, Fontana M. Determination of minimum CFRP pre-stress levels for fatigue crack prevention in retrofitted metallic beams. Engineering Structures, Vol. 84, 2015, 29-41.

[19] Bassetti A, Nussbaumer A, Hirt MA. Crack repair and fatigue life extension of riveted bridge members using composite materials. Bridge Engineering Conference, ESE-IABSE-FIB, Sharm E1 Sheikh, Vol. 1, 2000, 227-238.

[20] Tavakkolizadeh M, Saadatmanesh H. Fatigue Strength of Steel Girders Strengthened with Carbon Fiber Reinforced Polymer Patch. Journal of Structural Engineering, 2003, 186- 196.

[21] Kim YJ, Harries KA. Fatigue behavior of damaged steel beams repaired with CFRP strips. Engineering Structures, Vol. 33, 2011, 1491-1502.

[22] Yu QQ. Zhao XL, Al-Mahaidi R, Xiao ZG, Chen T, Gu XL. Tests on cracked steel plates with different damage levels strengthened by CFRP laminates. International Journal of Structural Stability and Dynamics, Vol. 14, 2014, 26.

[23] Liu H, Al-Mahaidi R, Zhao XL. Experimental study of fatigue crack growth behaviour in adhesively reinforced steel structures. Composite Structures, Vol. 90, no. 1, 2009, 12-20.

[24] Lepretre E, Chataigner S, Dieng L, Gaillet L. Fatigue strengthening of cracked steel plates with CFRP laminates in the case of old steel material, Construction and Building Materials, Vol. 174, 2018, 421-432.

[25] Moy S, Bloodworth A G. Strengthening a steel bridge with CFRP composites. ICE Proceedings - Structures and Buildings, Vol. 160(2), 2007, 81-93.

[26] Ghafoori E, Motavalli M. Innovative CFRP-Prestressing System for Strengthening Metallic Structures. Journal of Composites for Construction, Vol. 19(6), 2015, 04015006.

[27] Ghafoori E, Motavalli M, Nussbaumer A, Herwig A, Prinz GS, Fontana M. Design criterion for fatigue strengthening of riveted beams in a 120-year-old railway metallic bridge using pre-stressed CFRP plates. Composites Part B: Engineering, Vol.68, 2015, 1-13. 
[28] Zhao XL. FRP-strengthened metallic structures. Boca Raton, Fla.: CRC Press, 2014.

[29] Hu L, Feng P, Zhao XL. Fatigue design of CFRP strengthened steel members. Thin-Walled Structures, Vol. 119, 2017, 82-498.

[30] AASHTO. AASHTO LRFD bridge design specifications. Washington, DC: American Association of State Highway and Transportation Officials, 2012.

[31] EN1991: 2003. Eurocode 1: Actions on structures - Part 1-5: general actions : Thermal actions.

[32] Michels J, Widmann R, Czaderski C, Allahvirdizadeh R, Motavalli M. Glass transition evaluation of commercially available epoxy resins used for civil engineering. Composites Part B: Engineering, Vol.77, 2015, 484-493.

[33] Chataigner S, Caron JF, Benzarti K, Quiertant M, Aubagnac C. Use of a single lap shear test to characterize composite-to-concrete or composite-to-steel bonded interfaces. Construction and Building Materials, Vol.25(2), 2011, 468-478.

[34] Harries K, Dawood M. Behavior and Performance of FRP-to-Steel Bond. Transportation Research Record, Vol. 2313/2012, 2012, 181-188.

[35] Chataigner S, Gagnon A, Quiertant M, Benzarti K, Aubagnac C. Adhesively bonded composite reinforcements for steel structures: durability of the stress transfer. Proceedings of CICE conference, Rome, 2012.

[36] Fawzia S, Zhao XL, Al-Mahaidi R, Rizkalla S. Bond characteristics between CFRP and steel plates in double strap joints. Advances in Steel Construction, 2005, 17-28.

[37] Lepretre E, Chataigner S, Dieng L, Gaillet L, Gagnon A, Roth J, Leroy C. Experimental characterization of different adhesively bonded composite reinforcements for old steel structures. Proceedings of Structural Faults and Repair Conference.Edinburgh, 2016.

[38] Volkersen O. Die nietkraftverteilung in zugsbeanspruchten Nietverbondungen mit konstanten laschenquerschritten. Luftfahrtforschung, 1938, 41-47.

[39] Pham H, Al-Mahaidi R. Modelling of CFRP-concrete lap shear tests. Construction and Building Materials, Vol.21(4), 2005, 727-735.

[40] Xia S, Teng J. Behavior of FRP-to-steel bonded joints. International Symposium on Bond Behaviour of FRP in Structures (BBFS), (S. 419-426). Hong Kong, 2005.

[41] Wu C, Zhao XL, Al-Mahaidi R. Bond characteristics between ultra high modulus CFRP laminates and steel. Thin Walled Structures, Vol.51, 2012, 147-157.

[42] Heshmati M, Haghani R, El-Emrani M, André A. On the strength prediction of adhesively bonded FRP-steel joints using cohesive zone modelling. Theoretical and Appplied Fracture Mechanics, Vol.93, 2018, 64-78.

[43] Haghani R, Al-Emrani M. A new design model for adhesive joints used to bond FRP laminates to steel beams - Part A. Construction and Building Materials, Vol.34, 2012, 486-493.

[44] EOTA. Assessment procedure for durability of thin metallic composite panels, TR 038, 2012.

[45] Linghoff D, Haghani R, El-Emrani M. Carbon-fibre composites for strengthening steel structures. Thin-walled structures, Vol. 47, 2009,1048-1058.

[46] Zhao XL, Zhang L. State-of-the-art review on FRP strengthened steel structures. Engineering Structures, Vol.29 (8), 2007, 1808-1823.

[47] Dawood M, Rizkalla S. Environmental durability of a CFRP system for strengthening steel structures. Construction and Building Materials, Vol. 24(9), 2010,1682-1689.

[48] Benzarti K, Chataigner S, Quiertant M, Marty C, Aubagnac C. Accelerated ageing behaviour of the adhesive bond between concrete specimens and CFRP overlays. Construction and Building Materials, Vol. 25, 2011, 523-538. 
[49] Heshmati M, Haghani R, El-Emrani M. Environmental durability of adhesively bonded FRP/steel joints in civil engineering application. Composites Part B: Engineering, Vol. 81, 2015, 259 275.

[50] Ascione L et al. Prospect for new guidance in the design of FRP, Joint Research Centre, EUR 27666EN, 2016.

[51] Wu C, Zhao XL, Chiu WK, Al-Mahaidi R, Duan WH. Effect of fatigue loading on the bond behaviour between UHM CFRP plates and steel plates. Composites Part B: Engineering, Vol.50, 2013, 344-353.

[52] Chafi H, Optimisation des efforts dans un ancrage courbe collé acier/composite, Ph.D Thesis, University Paris Est, 2017 (in French). https://pastel.archives-ouvertes.fr/tel-01764926 


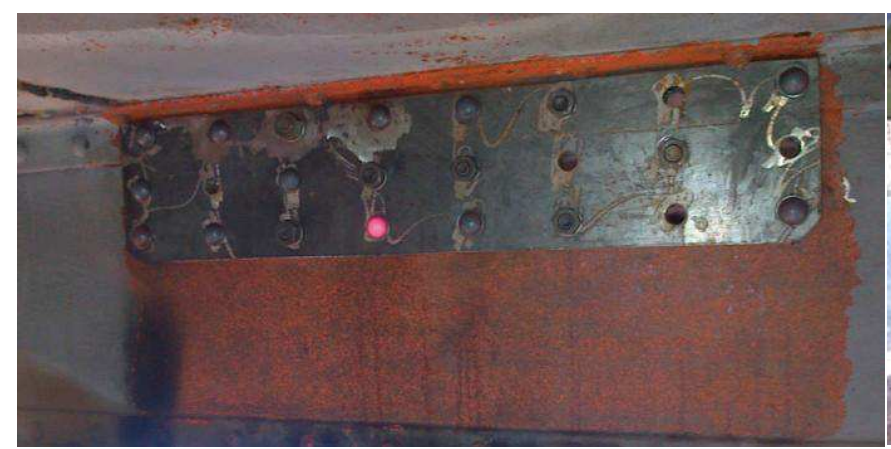

(a) Figure 1: Pictures of repair solutions using (a) additional riveted steel plate, and (b) adhesively bonded CFRP plates (application on a construction site in France)

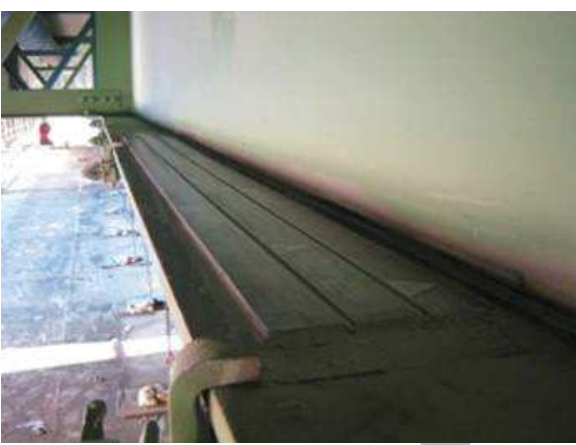

(b)

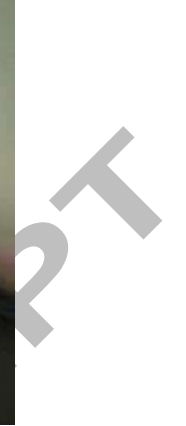
d 
(a)

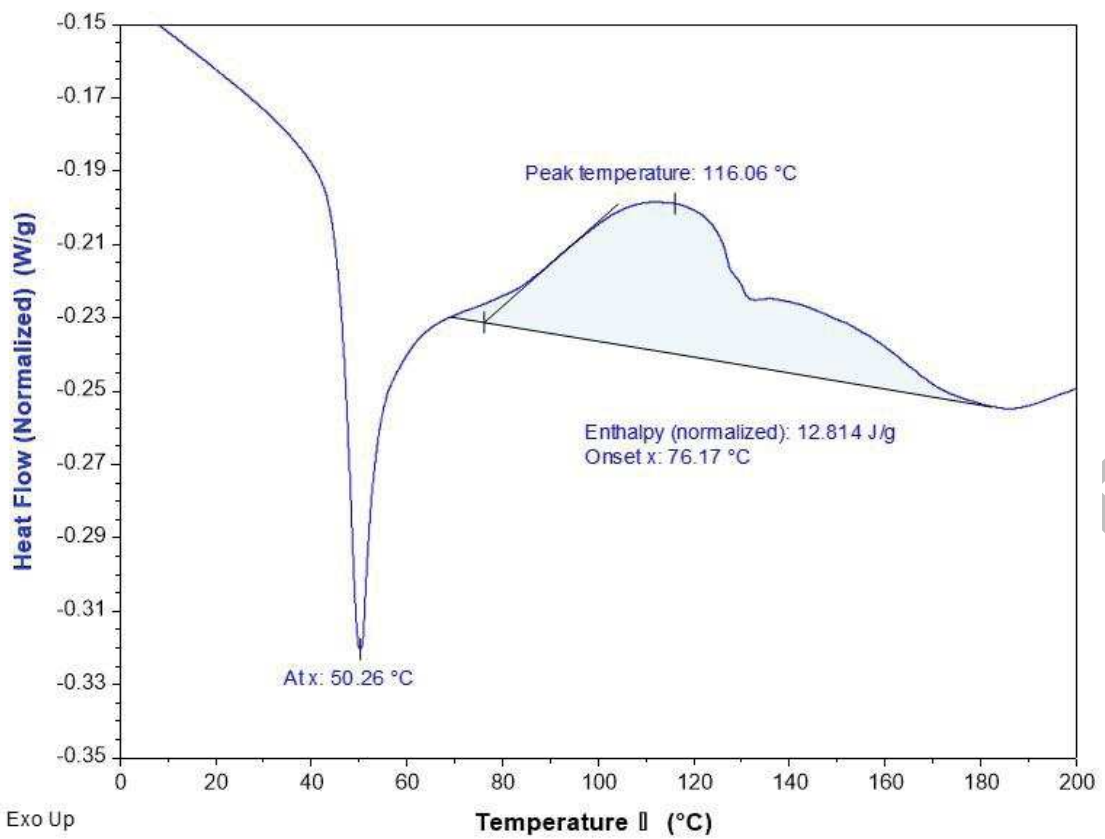

Exoup

Temperature $\left[\left({ }^{\circ} \mathrm{C}\right)\right.$

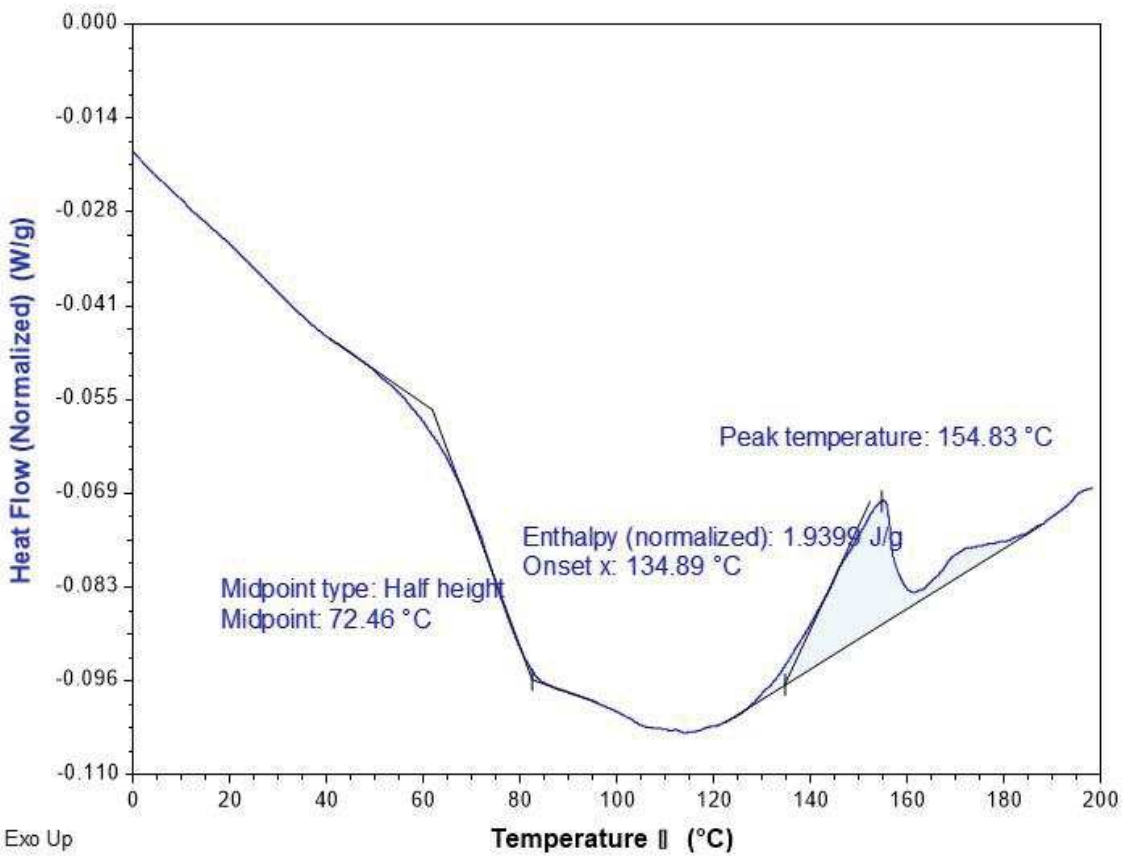

Figure 2: Examples of DSC thermograms for UREPOX Extra $2 \mathrm{C} / 2 \mathrm{~B}$ adhesive, after $24 \mathrm{~h}$ cure at $20^{\circ} \mathrm{C}$ (a), and after additional $1 \mathrm{~h}$ post-cure at $80^{\circ} \mathrm{C}(\mathrm{b})$. The heating rate is $10^{\circ} \mathrm{C} / \mathrm{min}$. 


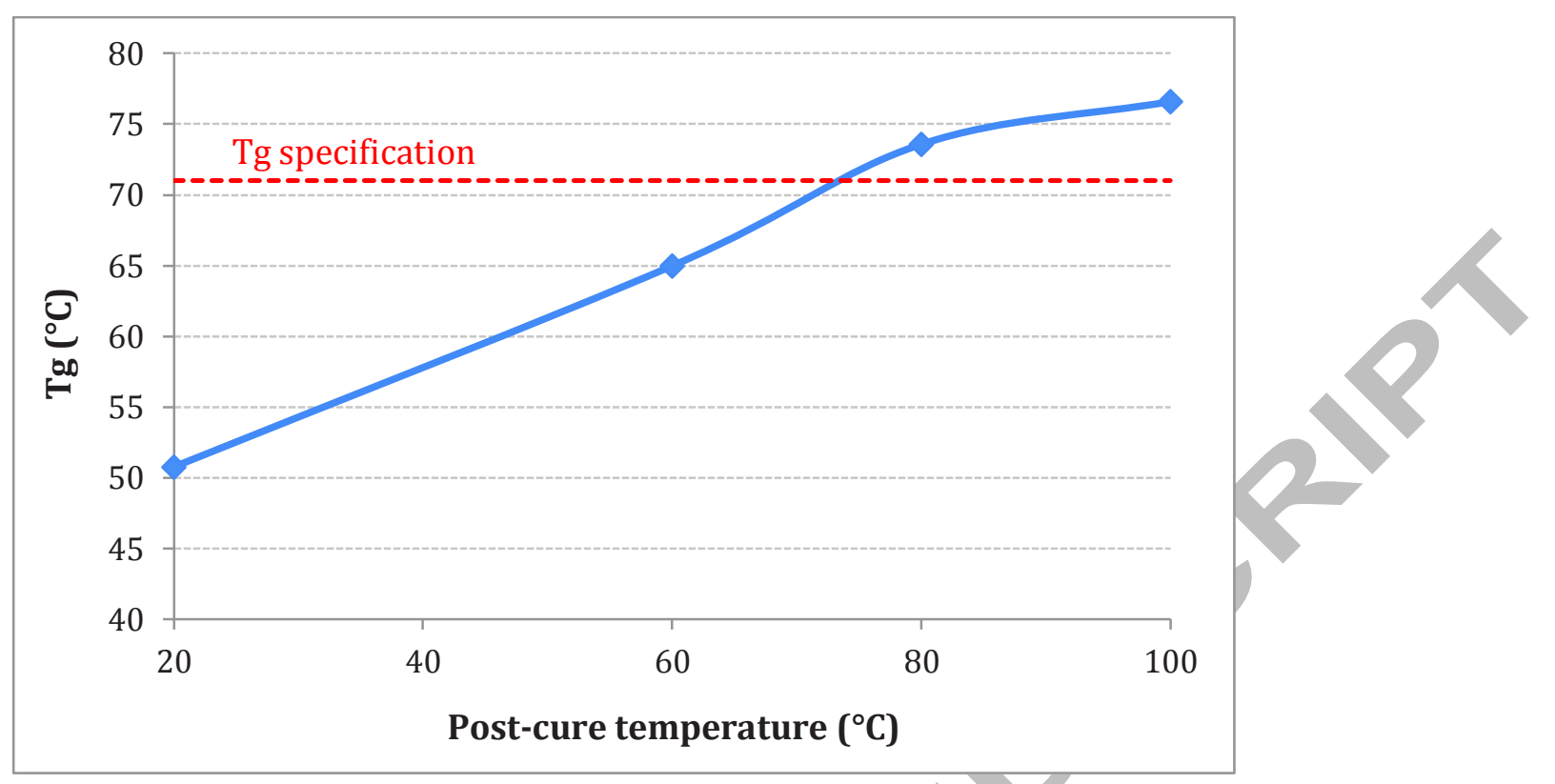

Figure 3: Evolution of Tg versus post-cure temperature for UREPOX Extra 2C/2B adhesive. 

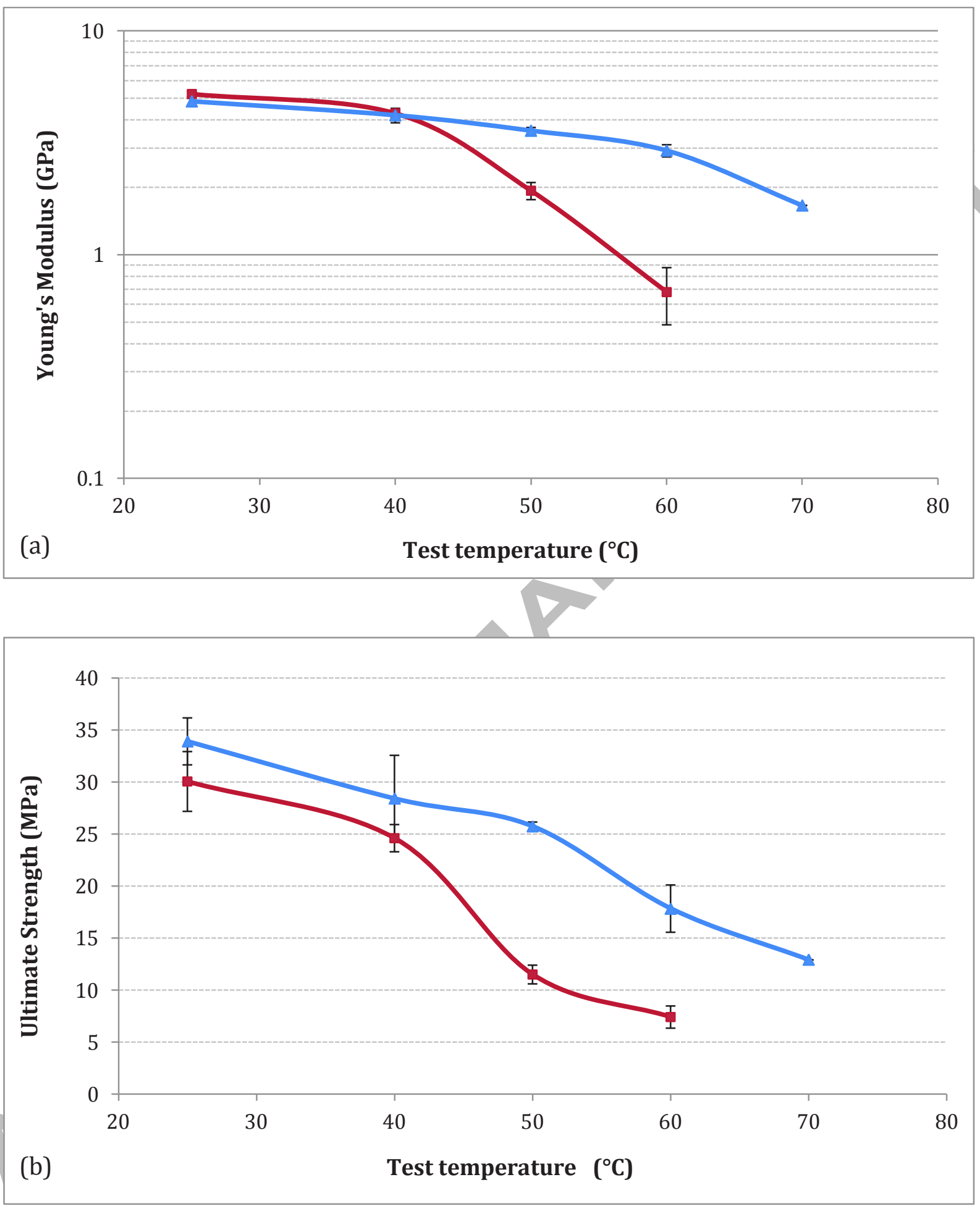


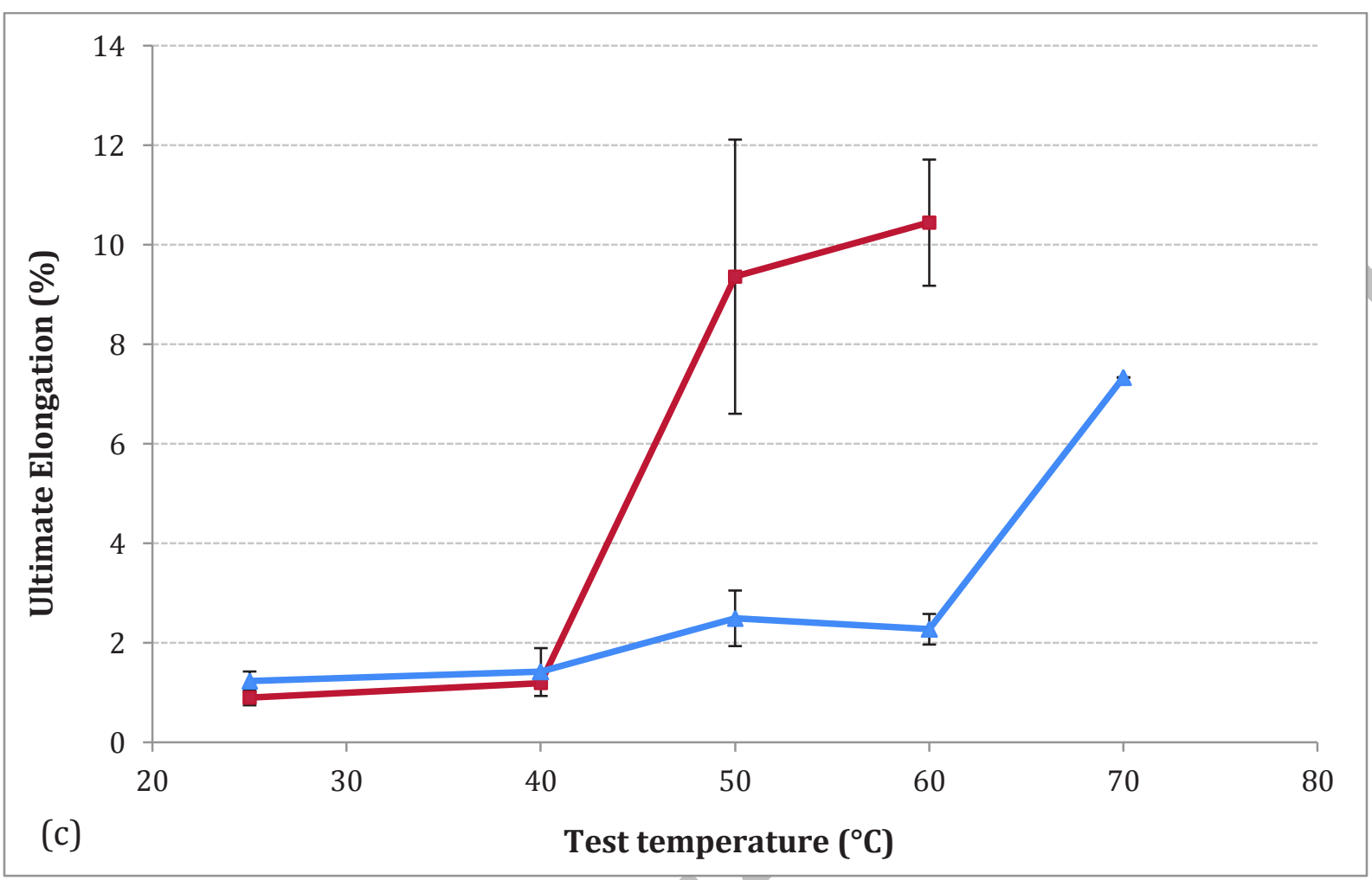

Figure 4: Evolution versus testing temperature of the tensile Young's Modulus (a), the tensile strength (b) and the ultimate elongation (c), for UREPOX Extra $2 \mathrm{C} / 2 \mathrm{~B}$ adhesive cured at $20^{\circ} \mathrm{C}(\boldsymbol{\square})$ and with additional post-cure at $80^{\circ} \mathrm{C}$ for $1 \mathrm{~h}(\mathbf{\Delta})$. 


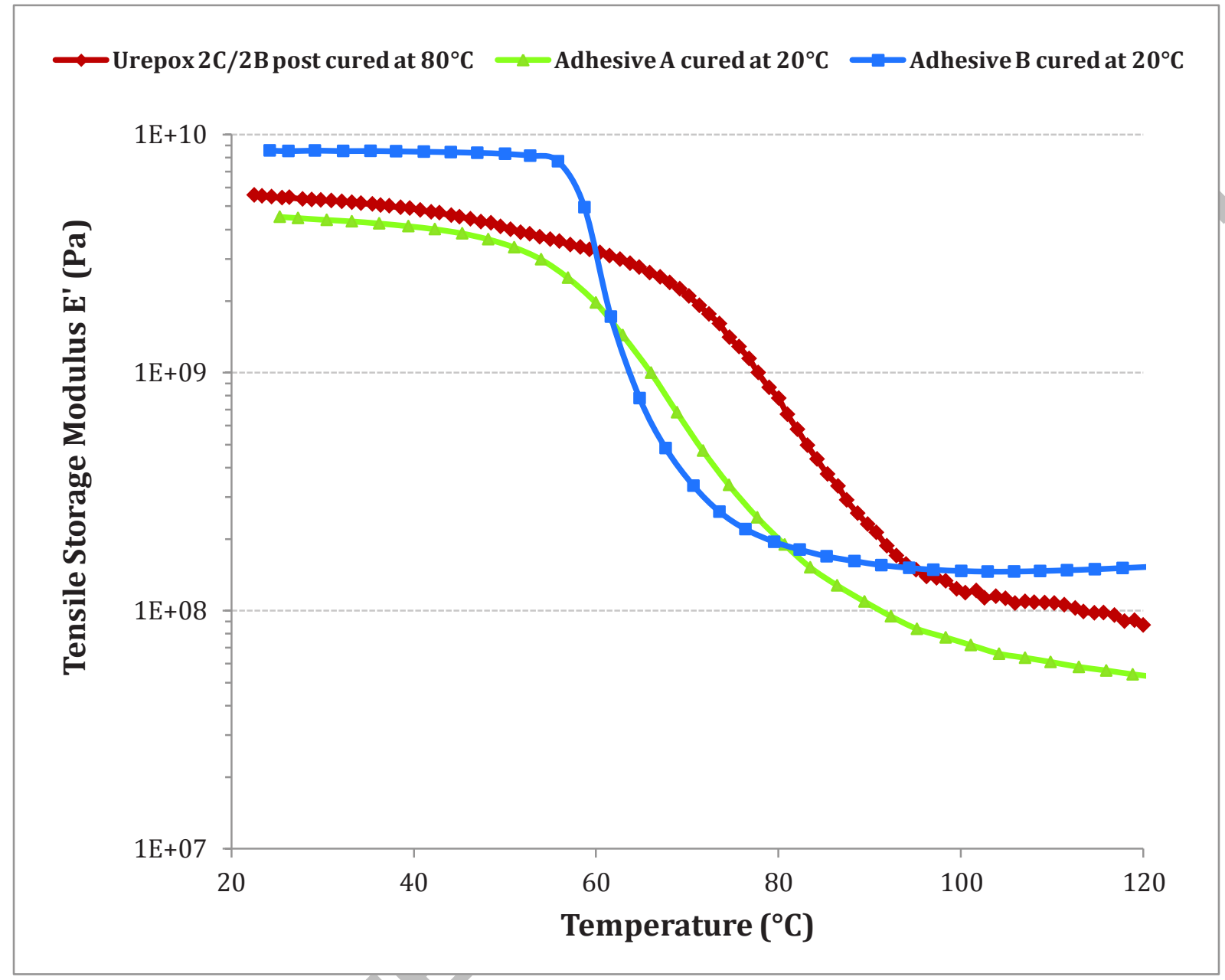

Figure 5: Evolutions of the storage modulus E' versus temperature for UREPOX Extra 2C/2B and 2 other commercial products (named Adhesives A and B), after polymerization according to the cure schemes used in the field.

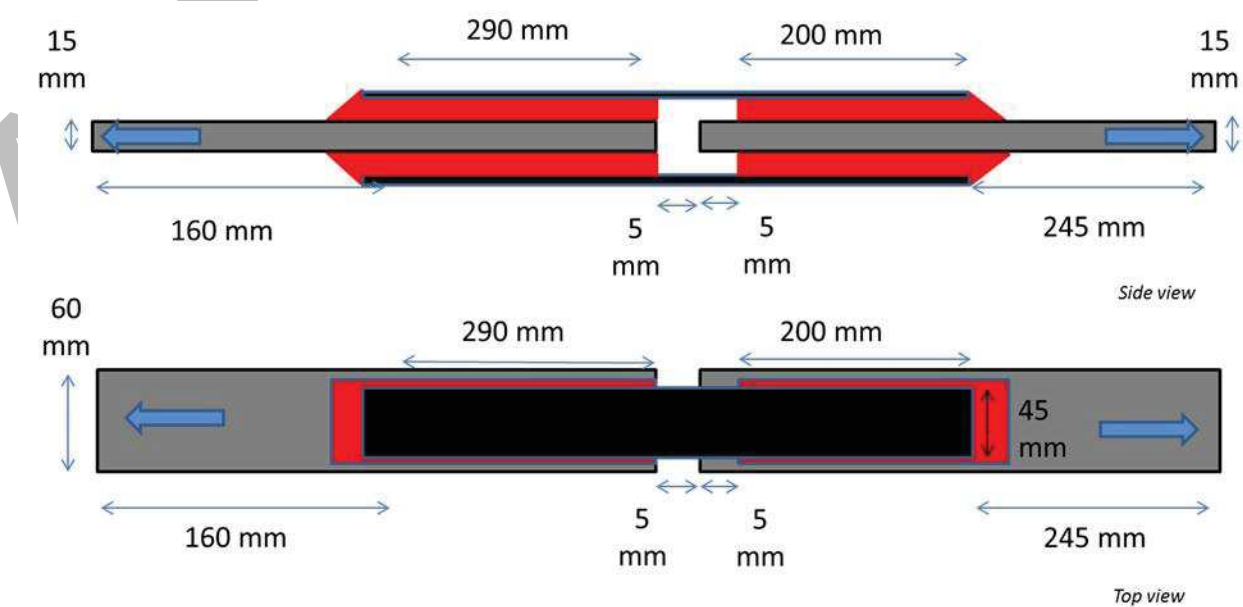

Figure 6: Geometry of the double-lap shear test specimens 


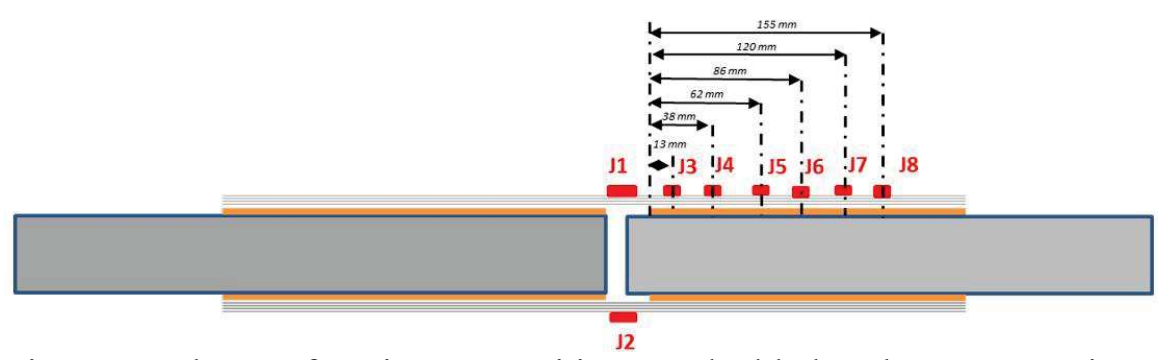

Figure 7: Scheme of strain gage positions on double lap shear test specimens

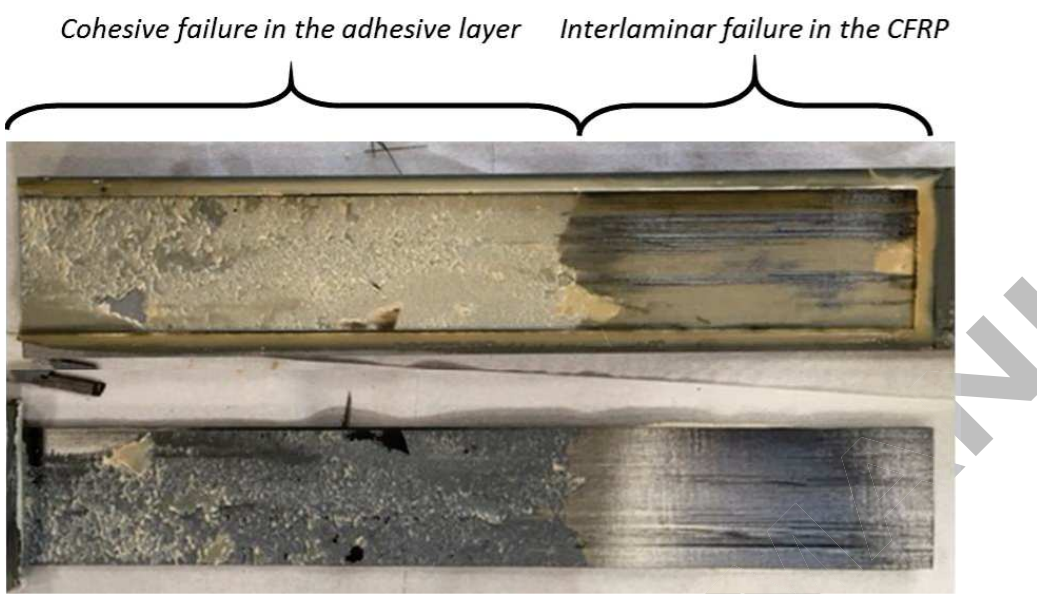

Figure 8: Photo of the observed failure mode (cohesive in the adhesive layer closed to the middle of the sample, and interlaminar in the CFRP plate)

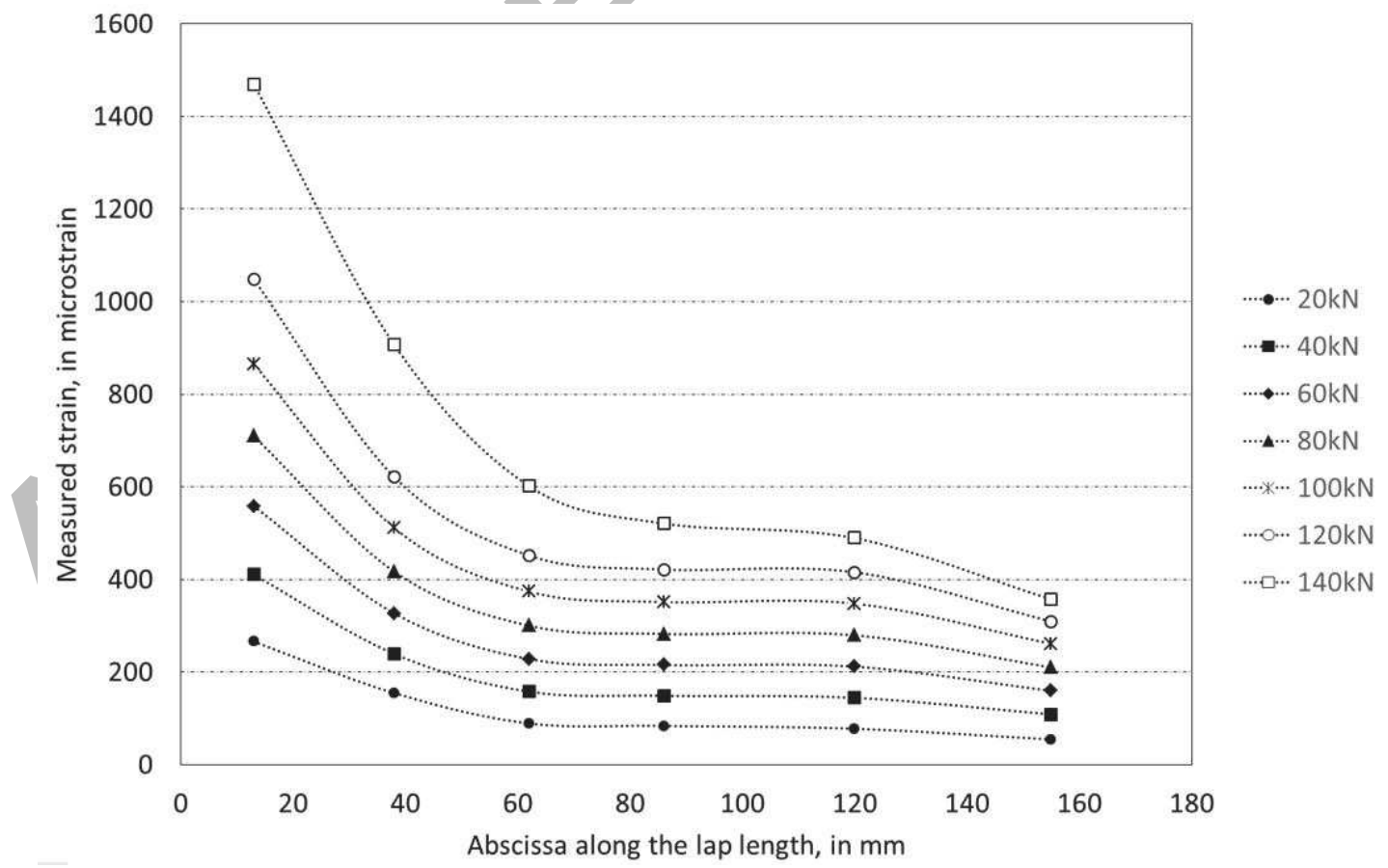

Figure 9: Strain profiles along the lap joint at various load levels, as recorded during a double lap shear test. 


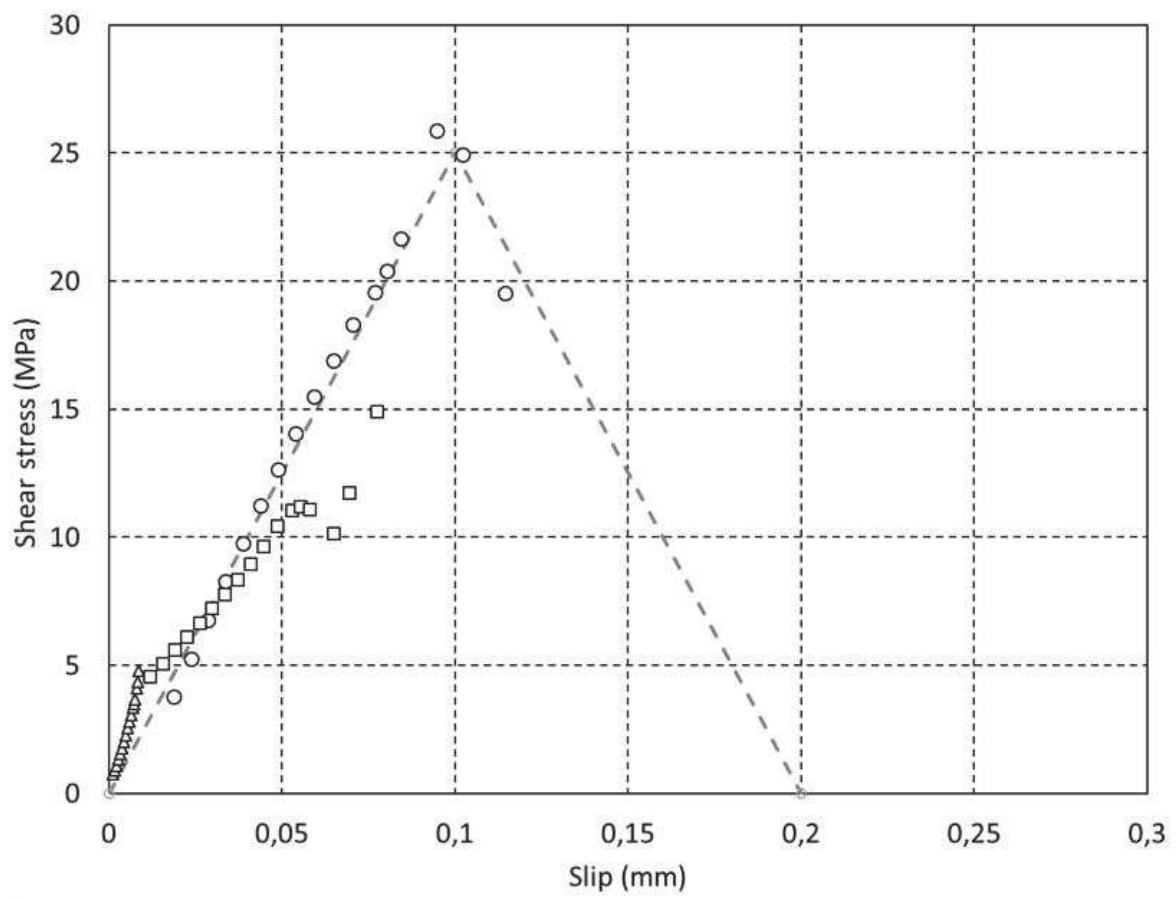

Figure 10: Determination of the cohesive zone model characteristics (dots: experimental data; dashed line: classical cohesive zone model).

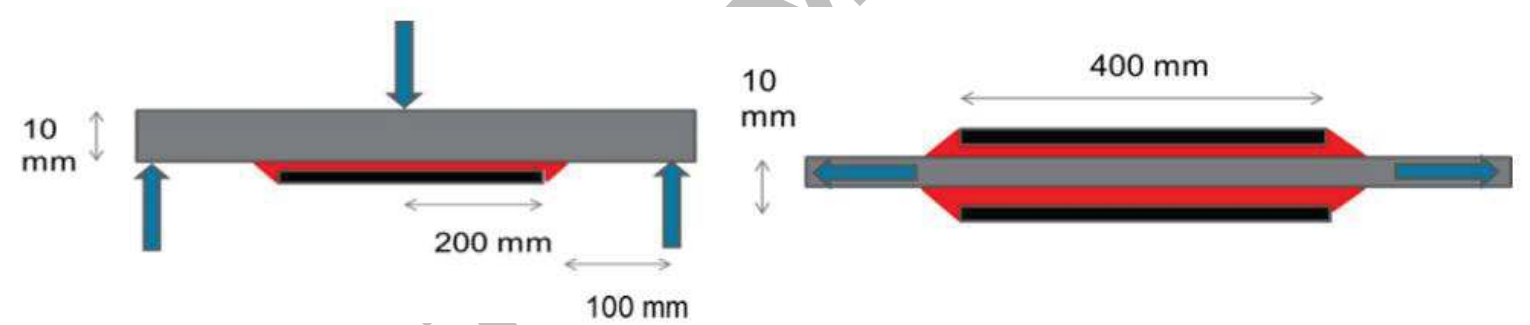

Figure 11: Scheme of the flexure test and the double strap test (from left to right)
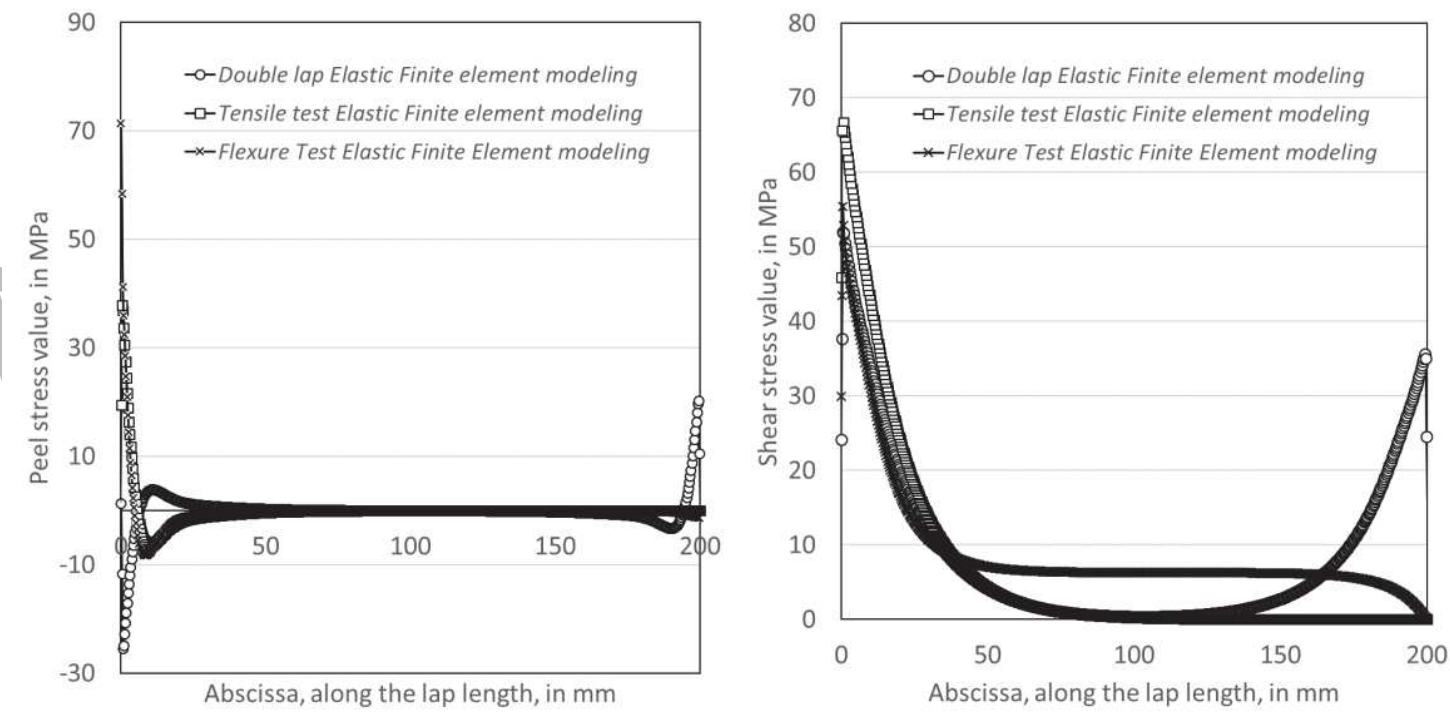

Figure 12 Peel and shear stress profiles along the bonded lap length for the 3 different test geometries, and for loads corresponding to average ultimate capacities 


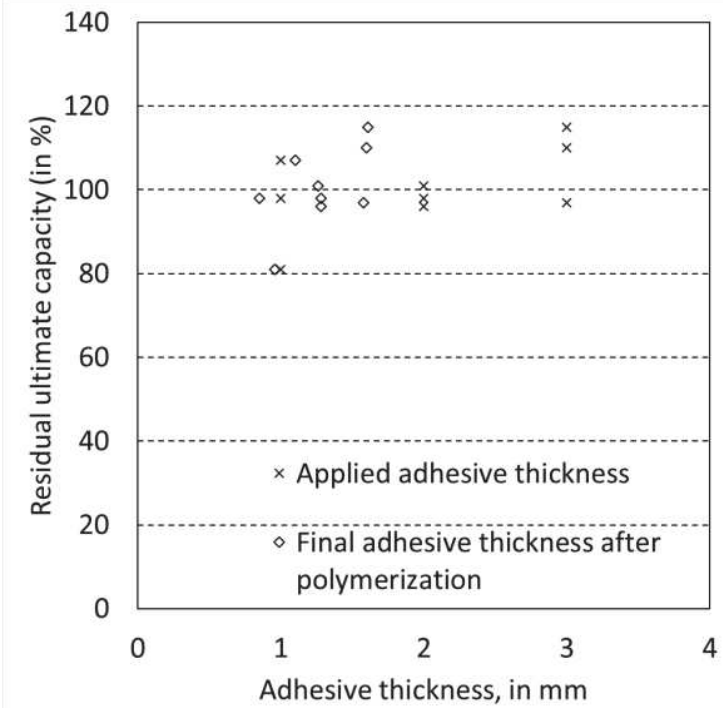

(a)

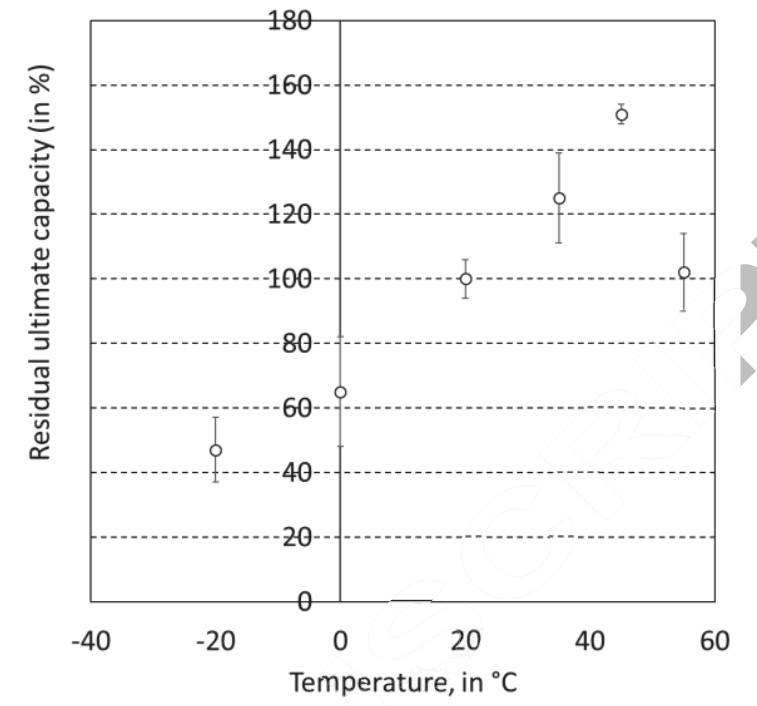

(b)

Figure 13: Influence of the thickness of the adhesive layer (a) and the test temperature (b) on the ultimate capacity as determined from double lap shear tests

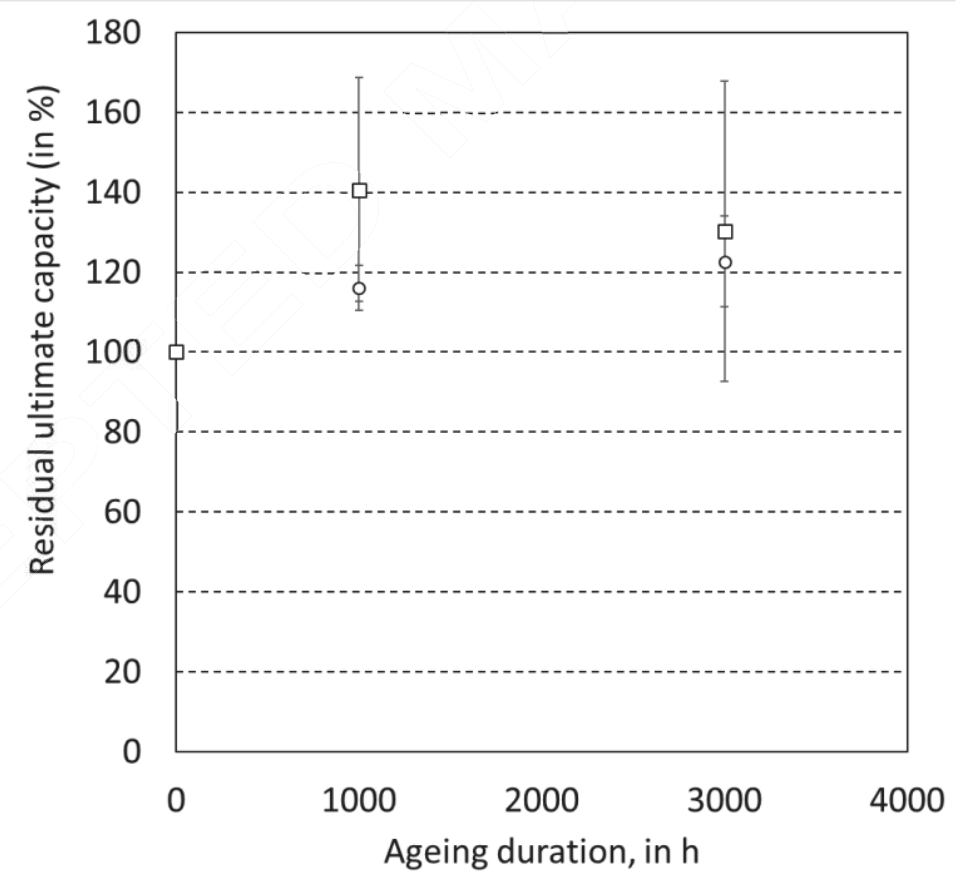

Figure 14: Influence of moist ageing on the ultimate capacity of the bonded UHM-CFRP / steel assembly. ( $\square$ ) refers to double lap test results and ( $\odot$ ) to single lap test results 


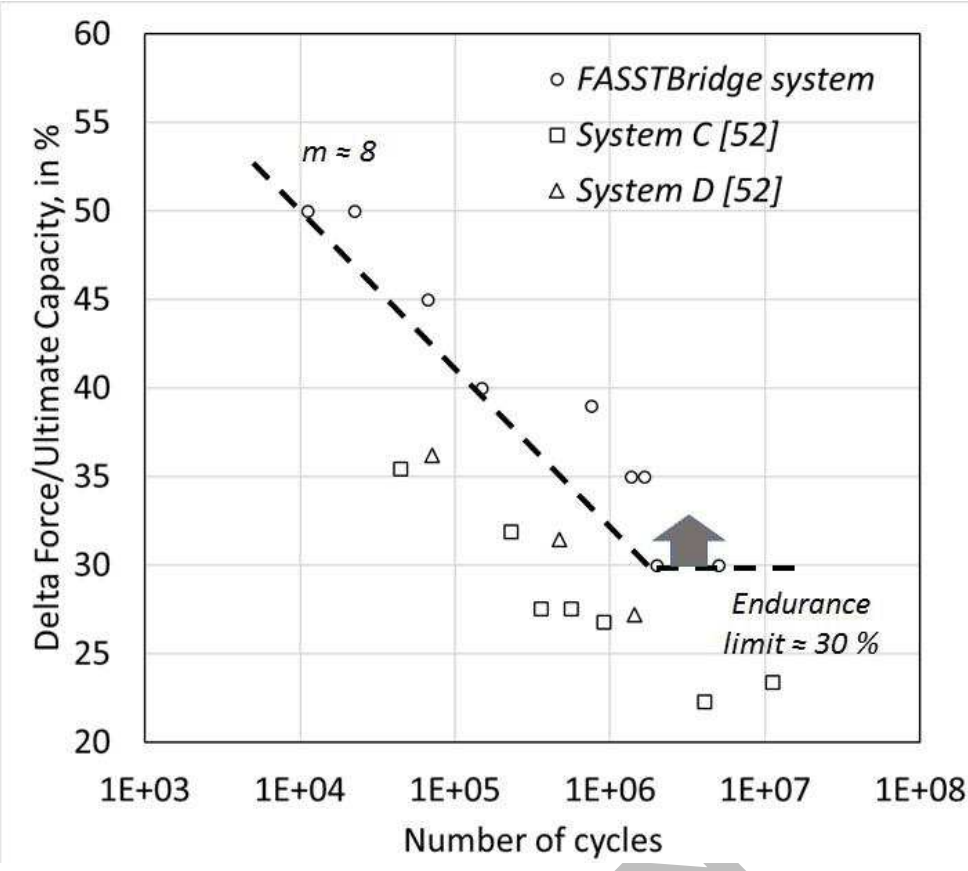

Figure 15: Compared results of fatigue tests (double lap shear configuration) for series of specimens made with Urepox 2C/2B adhesive and two other commercial adhesives [52] 
Table 1: Main properties of UREPOX 2C/2B polymer adhesive (data provided by Collanti Concorde and Ifsttar).

\begin{tabular}{|c|c|}
\hline Resin/Hardener Mix ratio & $100 / 15$ \\
\hline Texture of the mix & Thyxotropic Paste \\
\hline Brookfield viscosity at $20^{\circ} \mathrm{C}$ & 6000 Pa.s (Helipath Spindle ${ }^{\circ} 96,10 \mathrm{rpm}$ ) \\
\hline Specific weight & $1.52 \pm 0.4 \mathrm{~g} / \mathrm{cm} 3$ \\
\hline Temperature range for application & $5-35^{\circ} \mathrm{C}$ \\
\hline Tg after cure at $20^{\circ} \mathrm{C}$ (for few days) & $50^{\circ} \mathrm{C}$ (DSC with a heating rate of $\left.10^{\circ} \mathrm{C} / \mathrm{min}\right)$ \\
\hline $\mathrm{Tg}_{\infty}$ of the fully post-cured system & $76^{\circ} \mathrm{C}$ (DSC, second run) \\
\hline Pot life at $20^{\circ} \mathrm{C}$ (mass of $2.5 \mathrm{~kg}$ ) & 29 minutes \\
\hline Gel time at $20^{\circ} \mathrm{C}$ & $\begin{array}{l}1 \mathrm{~h} 30 \text { (DMA-Dynamic Mechanical Analysis, } \\
\text { for a mass of } \sim 10 \mathrm{~g} \text { ) }\end{array}$ \\
\hline Final hardening at $20^{\circ} \mathrm{C}$ & Minimum of 5 hours. \\
\hline
\end{tabular}

Table 2: Values of $T g$, and degrees of cure obtained from DSC thermograms for UREPOX 2C/2B adhesive subjected to various cure schedules.

\begin{tabular}{lcc}
\hline Cure schedule & $\boldsymbol{T}_{g}\left({ }^{\circ} \mathrm{C}\right)$ & Degree of cure $\alpha(\%)$ \\
\hline $24 \mathrm{~h}$ at $20^{\circ} \mathrm{C}$ & 50.2 & 93 \\
$24 \mathrm{~h}$ at $20^{\circ} \mathrm{C}+1 \mathrm{~h}$ at $60^{\circ} \mathrm{C}$ & 64.4 & 99.2 \\
$24 \mathrm{~h}$ at $20^{\circ} \mathrm{C}+1 \mathrm{~h}$ at $80^{\circ} \mathrm{C}$ & 72.5 & 99 \\
$24 \mathrm{~h}$ at $20^{\circ} \mathrm{C}+1 \mathrm{~h} \mathrm{at} 100^{\circ} \mathrm{C}$ & 76.5 & 99.7 \\
\hline
\end{tabular}

Table 3: Experimental results obtained by the various laboratories for double lap shear tests

\begin{tabular}{llll}
\hline & TECNALIA & MPA Stuttgart & IFSTTAR \\
\hline Average ultimate capacity, in $\boldsymbol{k} \boldsymbol{N}$ & 163 & 161 & 170 \\
Standard deviation, in $\boldsymbol{k} \boldsymbol{N}$ & 12 & 21 & 12 \\
Dispersion, in \% & 7 & 14 & 7 \\
\hline
\end{tabular}


Table 4: Experimental results obtained for double strap and flexure tests

\begin{tabular}{|c|c|c|c|}
\hline & Double lap shear test & Double strap test & Flexure test \\
\hline Average ultimate capacity, in $k N$ & 170 & 233 & 6.1 \\
\hline Standard deviation, in $k N$ & 12 & 28 & 0.1 \\
\hline Dispersion, in \% & 7 & 12 & 2 \\
\hline $\begin{array}{l}\text { Average experimental ultimate } \\
\text { CFRP strain, in microstrain }\end{array}$ & 1688 & 1266 & 2355 \\
\hline $\begin{array}{l}\text { Calculated ultimate CFRP strain, } \\
\text { in microstrain }\end{array}$ & 1785 & 1164 & \\
\hline
\end{tabular}

Table 5: Ultimate shear and peel stress values obtained by finite element analysis for the experimental average ultimate capacities

\begin{tabular}{lllll}
\hline & $\begin{array}{l}\text { Double lap test } \\
\text { (first edge) }\end{array}$ & $\begin{array}{l}\text { Double lap test } \\
\text { (second edge) }\end{array}$ & $\begin{array}{l}\text { Double } \\
\text { strap test }\end{array}$ & $\begin{array}{l}\text { Flexure } \\
\text { test }\end{array}$ \\
\hline Maximum shear stress, in MPa & 52 & 36 & 67 & 55 \\
Maximum peel stress, in MPa & -25 & 20 & 37 & 40 \\
Mixed criterion [16] & 41 & 47 & 88 & 78 \\
Tresca criterion [36] & 32 & 26 & 44 & 45 \\
\hline
\end{tabular}




\section{Highlights}

- An adhesively bonded CFRP system was developed for the preventive strengthening of steel structures against fatigue damage.

- This system consists of a commercially available UHM CFRP plate and a formulated hybrid epoxy/polyurethane adhesive.

- Characterizations on the bulk adhesive proved that a post-cure treatment at $80^{\circ} \mathrm{C}$ for 1 $\mathrm{h}$ was necessary to reach the required glass transition temperature.

- A test plan on bonded UHM-CFRP/steel assemblies highlighted the influence of various geometrical and environmental factors on ultimate properties and durability. 